\title{
Blue Photosensitizer with Copper(II/I) Redox Mediator for Efficient and Stable Dye-Sensitized Solar Cells
}

\author{
Yameng Ren, Natalie Flores-Díaz, Dan Zhang, Yiming Cao, Jean-David Decoppet, \\ George Cameron Fish, Jacques-E. Moser, Shaik Mohammed Zakeeruddin, Peng Wang,* \\ Anders Hagfeldt,* and Michael Grätzel**
}

Dye-sensitized solar cells (DSCS) based on copper(II/I) redox mediators have recently achieved notable performance progress through tailoring the ligand structure of the copper complexes, exploiting cosensitization, and introducing an advanced device structure. In order to further improve the power conversion efficiency (PCE), it is imperative to develop wide spectral-response photosensitizers compatible with the copper(II/I) redox mediators while attaining a high $V_{\text {oc }}$. Herein, a blue photosensitizer coded $\mathbf{R 7}$ is reported, which is purposely designed for highly efficient DSCs with copper-based electrolytes. R7 features a strong electron-donating segment of 9,19-dihydrobenzo[ $\left.{ }^{\prime}, 10^{\prime}\right]$ phenanthro $\left[3^{\prime}, 4^{\prime}: 4,5\right]$ thieno[3,2-b]benzo[1,10]phenanthro[3,4-d] thiophene conjugated with a bulky auxiliary donor $\mathrm{N}$-(2,4'-bis(hexyloxy)-[1,1'-biphenyl]-4yl)-2,4'-bis(hexyloxy)- $N$-methyl-[1,1'-biphenyl]-4-amine and the electron acceptor 4-(7-ethynylbenzo[c][1,2,5]thiadiazol-4-yl)benzoic acid. The blue dye R7 with bulkier auxiliary donor moiety in the DSC largely outperforms the reference dye R6, which has a smaller bis(4-(hexyloxy)phenyl)amine donor unit. Transient absorption spectroscopy and electrochemical impedance spectroscopy measurements show that the R7 based DSC has a higher charge separation yield, a higher charge collection efficiency, and lower charge recombination with the copper electrolyte than the R6 based counterpart. A cosensitized system of R7 and $\mathrm{Y} 123$ for the DSC presents an outstanding PCE of $12.7 \%$ and retains $90 \%$ of its initial value after $1000 \mathrm{~h}$ of light soaking under 1 sun at $45^{\circ} \mathrm{C}$.

\section{Introduction}

Clear manifestations of the impact of climate change in the past few years have raised global concern. It is appealed to

Dr. Y. Ren, Dr. Y. Cao, J.-D. Decoppet, Dr. S. M. Zakeeruddin,

Prof. M. Grätzel

Laboratory of Photonics and Interfaces

Institute of Chemical Sciences and Engineering

École Polytechnique Fédérale de Lausanne (EPFL)

Lausanne 1015, Switzerland

E-mail: michael.graetzel@epfl.ch

Dr. Y. Ren, Prof. P. Wang

Department of Chemistry

Zhejiang University

Hangzhou 310028, China

E-mail: pw2015@zju.edu.cn

The ORCID identification number(s) for the author(s) of this article can be found under https://doi.org/10.1002/adfm.202004804. reduce the consumption of fossil fuels while stressing the need to develop a completely renewable and sustainable energy matrix. Cost-effective dye-sensitized solar cells (DSCs $)^{[1]}$ have attracted substantial attentions through analysis on functional interfaces, ${ }^{[2,3]}$ outer-sphere redox couples, ${ }^{[4-10]}$ and photosensitizers ${ }^{[11-20]}$ since the mesoscopic DSC first report in 1991. The record power conversion efficiency (PCE) of DSCs has reached $14.3 \%$ based on cobalt-based electrolytes in 2015,[16] while our group obtained the best-certified efficiency of $12.25 \% \quad\left(V_{\text {oc }}=1.0203 \mathrm{~V}\right.$, $J_{\mathrm{sc}}=15.17 \mathrm{~mA} \mathrm{~cm}{ }^{-2}$, fill factor $=79.1 \%$ ) reported by NREL in 2019.[21] Impressive practical applications of DSC panels have also been deployed to building glass façades of the SwissTech Convention Center ${ }^{[22]}$ and Science Tower Graz. ${ }^{[23]}$

Recently, the use of copper complexes as redox mediators in DSCs has markedly increased, mainly because their higher oxidation potentials, compared to the commonly used iodide/triiodide and cobalt complexes, have enabled a high open-circuit photovoltages $\left(V_{\text {oc }}\right)$ of over $1.0 \mathrm{~V} \cdot{ }^{[10,24-33]}$ Moreover, low internal reorganization energies, fast electron transfer rates, and fast diffusion of copper complexes make them promising to enhance the overall performance of DSCs. ${ }^{10]}$ The $\mathrm{Cu}(\mathrm{II} / \mathrm{I})$ redox mediator of $\left[\mathrm{Cu}^{2+/+}(\text { tmby })_{2}\right](\mathrm{TFSI})_{2 / 1}$ (tmby=4,4',6,6'-tetramethyl-2,2'-bipyridine;

N. Flores-Díaz, D. Zhang, Prof. A. Hagfeldt

Laboratory of Photomolecular Science

Institute of Chemical Sciences and Engineering

École Polytechnique Fédérale de Lausanne (EPFL)

Lausanne 1015, Switzerland

E-mail: anders.hagfeldt@epfl.ch

G. C. Fish, Prof. J.-E. Moser

Photochemical Dynamics Group

Institute of Chemical Sciences and Engineering

École Polytechnique Fédérale de Lausanne (EPFL)

Lausanne 1015, Switzerland

DOI: $10.1002 / \mathrm{adfm} .202004804$ 
TFSI = bis(trifluoromethylsulfonyl)imide), also referred as $\mathrm{Cu}$ (tmby) $2_{2}^{2+/+}$, was studied intensively in DSCs and some important progresses have been achieved. ${ }^{[25-31]}$ Nonetheless, the moderate values of short-circuit photocurrent density $\left(U_{\text {sc }}\right)$ reached by the copper complex-based DSCs impede further PCE enhancement. ${ }^{[10,24-28,31-33]}$ Photosensitizers play a vital role in harvesting sunlight or artificial light to generate charge carriers. The molecular structure of the photosensitizer affects the adsorption of dyes on the $\mathrm{TiO}_{2}$ surface and in turn the charge generation and collection yields. ${ }^{[34-36]}$ Therefore, a crucial strategy to improve the $J_{\mathrm{sc}}$ of a DSC consists of judicious design of the photosensitizer with properly extended spectral response that is compatible with copper-based electrolytes meanwhile depressing the interfacial charge recombination.

Here, we report a new blue dye coded R7, featuring a strong electron-donating polycyclic aromatic hydrocarbon (PAH) core, 9,19-dihydrobenzo[1,10']phenanthro[ $\left.3^{\prime}, 4^{\prime}: 4,5\right]$ thieno[3,2b]benzo[1,10]phenanthro[3,4-d]thiophene (BPT2) conjugated with an bulky auxiliary donor $N$-(2',4'-bis(hexyloxy)-[1, $1^{\prime}$ biphenyl]-4-yl)-2',4'-bis(hexyloxy)- $N$-methyl-[1,1'-biphenyl]-4 amine (generally denoted as Hagfeldt donor) and a famous electron acceptor 4-(7-ethynylbenzo[c][1,2,5]thiadiazol-4-yl) benzoic acid (EBTBA). The molecular structure of R7 is presented in Figure 1a. Subsequently, a detailed comparison with a wide spectral-response dye R6 (Figure 1a) characteristic of a smaller bis(4-(hexyloxy)phenyl)amine (BPA) donor unit is drawn. ${ }^{[17]}$ The DSCs based on the blue dye R7 in combination

a)

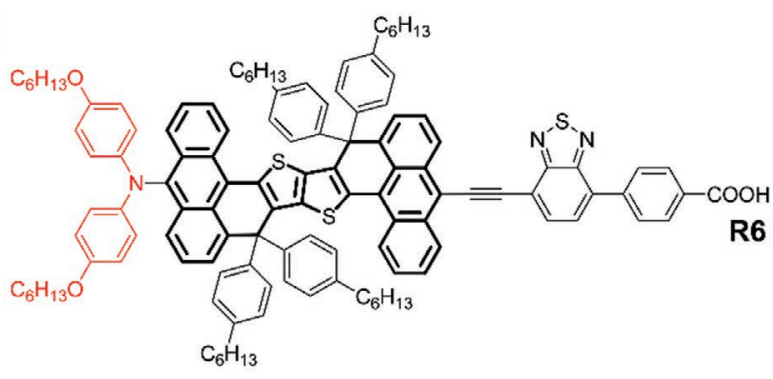

b)

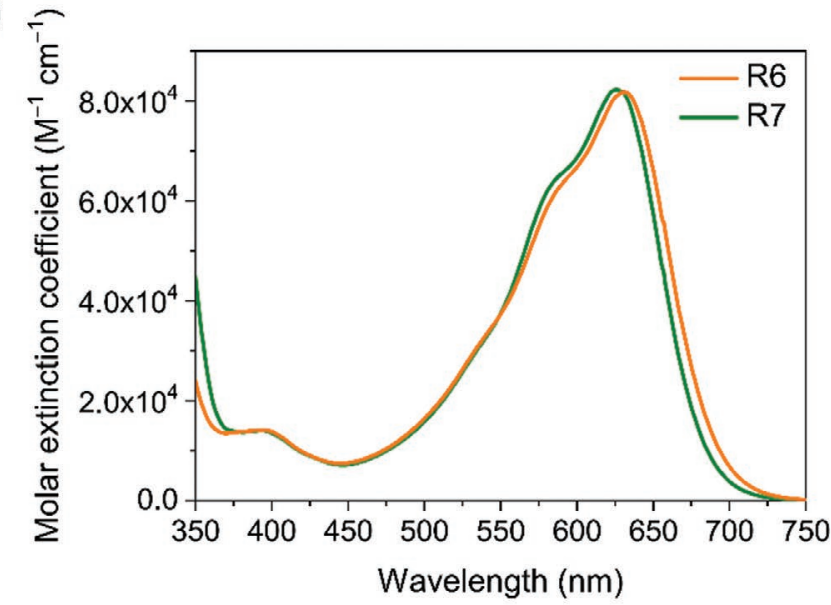

with the $\mathrm{Cu}$ (tmby) $2^{2+/ 1+}$ electrolyte show superior photovoltaic performance to the counterparts based on the reference dye R6. We employed transient absorption spectroscopy (TAS) and electrochemical impedance spectroscopy (EIS) measurements to reveal the impacts of the Hagfeldt donor and BPA donor on the charge separation yield, the charge collection efficiency, and the interfacial charge recombination rates. Cosensitization of $\mathrm{R} 7$ with the well-known organic dye $\mathrm{Y} 123^{[37]}$ greatly improves the performance of the device, leading to an outstanding PCE of $12.7 \%$ under simulated AM $1.5 \mathrm{G}$ sunlight, which impressively also maintains $90 \%$ of its initial value after $1000 \mathrm{~h}$ of continuous full sunlight soaking at $45^{\circ} \mathrm{C}$.

\section{Results and Discussion}

The blue dye R7 with the bulky Hagfeldt donor shows a similar UV-vis spectrum as R6 in THF, as shown in Figure 1b. An intense absorption peak for R7 is observed at around $626 \mathrm{~nm}$, slightly blue-shifted than that of R6 (630 nm). The maximal molar extinction coefficients of R7 and R6 are $85.5 \times 10^{3} \mathrm{M}^{-1} \mathrm{~cm}^{-1}$ and $81.8 \times 10^{3} \mathrm{M}^{-1} \mathrm{~cm}^{-1}$, respectively. The strong light harvesting capacity of the blue dyes enables the light harvesting efficiency to approach $100 \%$ even using thin mesoporous $\mathrm{TiO}_{2}$ films in DSCs, which is advantageous for charge collection and diffusion of redox mediator species.
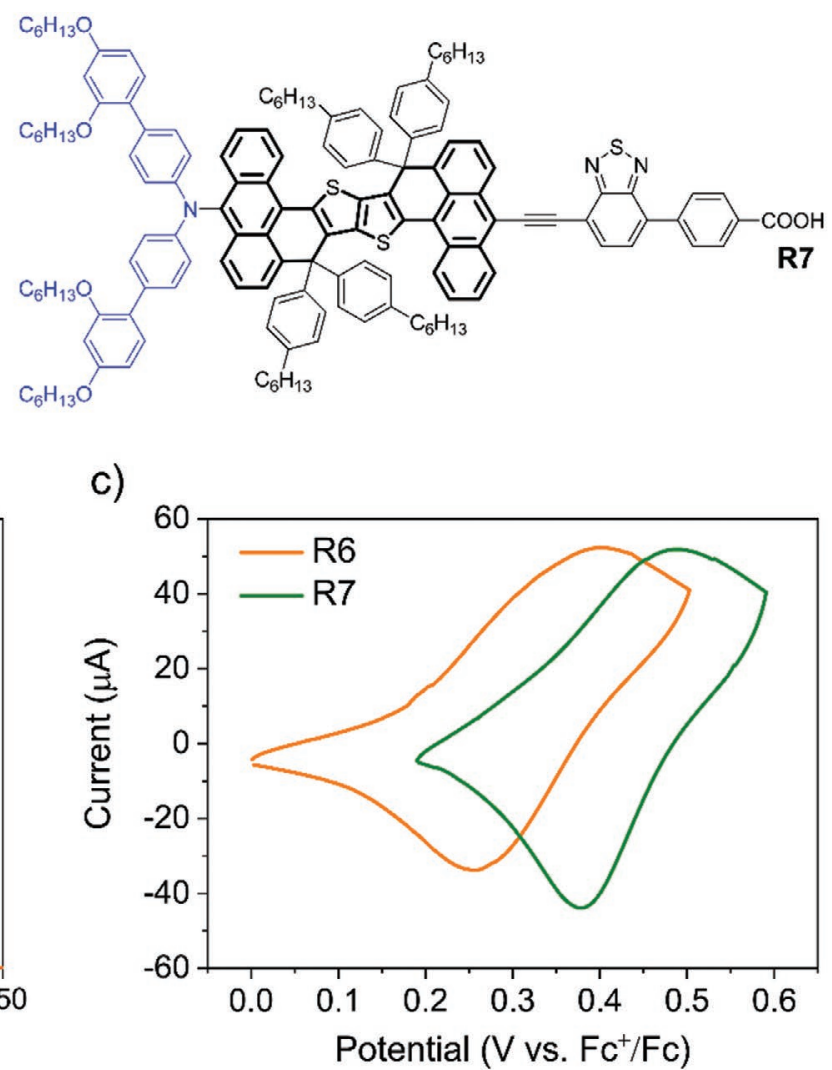

Figure 1. a) Molecular structure of the anthracene-based polycyclic aromatic hydrocarbon (PAH) dyes R6 and R7 characteristic of BPT2 in bold conjugated with BPA donor in red color and Hagfeldt donor in blue color, respectively. b) Molar extinction coefficient of R6 and R7 dissolved in THF as a function of wavelength. c) Cyclic voltammograms of R6, R7 dyes adsorbed on $\mathrm{TiO}_{2} / \mathrm{FTO}$ electrode in $0.1 \mathrm{M} \mathrm{LiTFSI}$ acetonitrile solution. Scan rate: $10 \mathrm{mV} \mathrm{s}^{-1}$. 

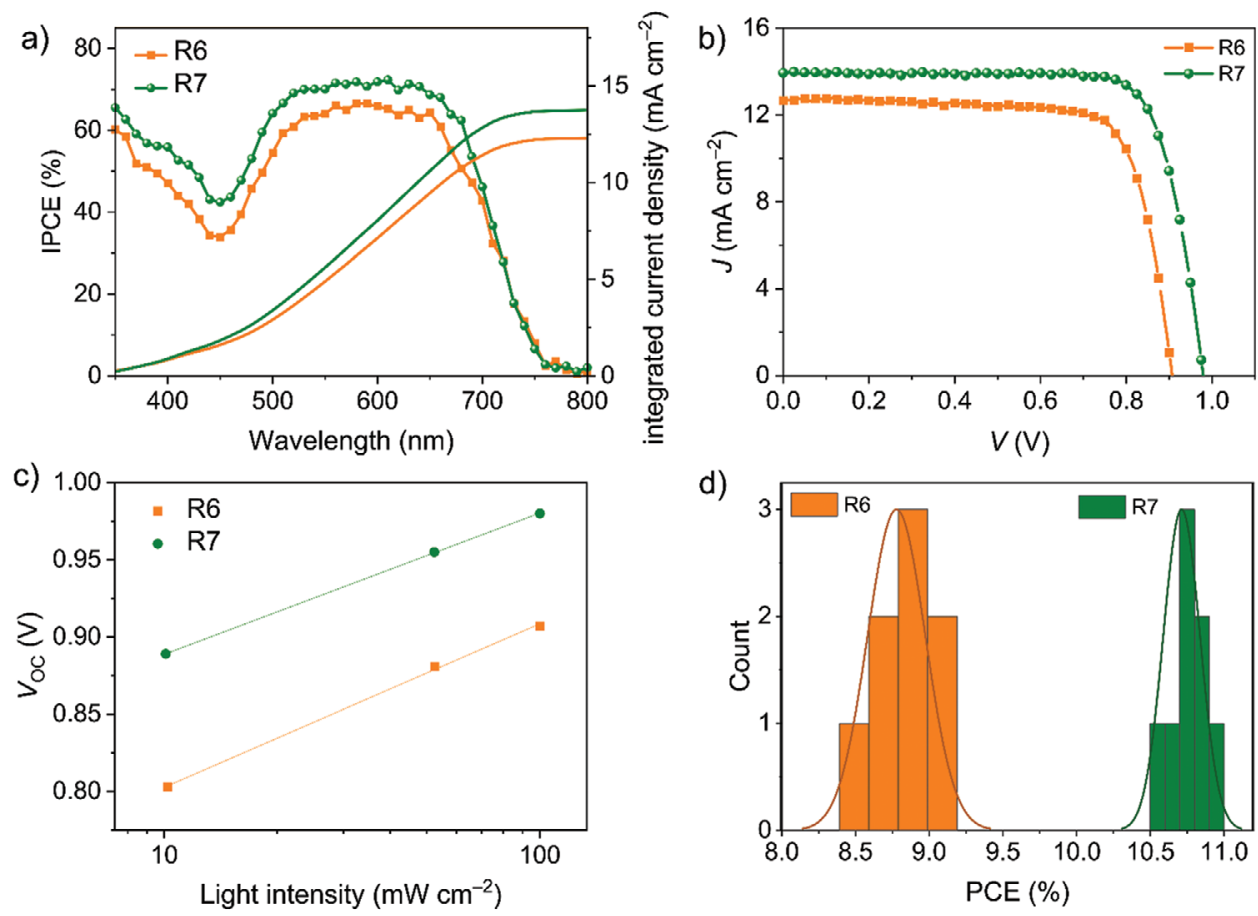

Figure 2. a) Incident photon-to-electron conversion efficiencies (IPCEs) at a set of wavelengths of incident monochromatic lights, and integrated current densities. b) Current density-voltage $(U-V)$ curves measured under simulated full sunlight conditions for DSCs. c) $V_{\text {oc }}$ as a function of light intensity of the DSCs based on R6 and R7. d) The PCE histogram of DSCs based on R6 and R7.

Cyclic voltammetry (CV) curves of the blue dyes R6 and R7 sensitized $\mathrm{TiO}_{2}$ films in conjunction with $0.1 \mathrm{M}$ LiTFSI acetonitrile electrolyte are shown in Figure 1c. The found first oxidation potentials are 0.33 and $0.43 \mathrm{~V}$ versus the formal potential of the reference ferrocene/ ferrocenium redox couple for the R6 and R7, correspondingly. The oxidation potential of R7 adsorbed on the $\mathrm{TiO}_{2}$ surface is found to be $1.05 \mathrm{~V}$ versus standard hydrogen electrode (SHE), higher than that of $\left[\mathrm{Cu}^{+}(\mathrm{tmby})_{2}\right]$ TFSI being $0.87 \mathrm{~V}^{[10]}$ ensuring ample driving force for dye regeneration. The oxidation potential of $\mathrm{R} 6$ on the $\mathrm{TiO}_{2}$ surface is $0.95 \mathrm{~V}$ versus SHE, which may meet the energetic barriers for the dye regeneration giving its small driving force of merely $80 \mathrm{mV}$. The more positive oxidation potential of R7 than R6 can be attributed to the twist at the biphenyl moieties and in turn a weaker conjugation between the electron donating groups and the central triphenylamine core.

DSCs with the blue sensitizers in conjunction with $\left[\mathrm{Cu}(\text { tmby })_{2}\right]^{2+/ 1+}$ redox shuttles were fabricated and characterized according to the Experimental section. The incidentphoton-to-current conversion efficiency (IPCE) spectra are shown in Figure 2a. The DSC based on R7 has an IPCE with a peak value of $72 \%$, being higher than the counterpart based on R6 with a peak of $66 \%$. Figure $2 \mathrm{~b}$ shows the current density-voltage $(J-V)$ curves of DSCs measured under simulated standard AM 1.5G, $100 \mathrm{~mW} \mathrm{~cm}{ }^{-2}$ condition. Their photovoltaic parameters under varying sunlight intensities are tabulated in Table 1 and $J-V$ curves under different sunlight intensities are presented in Figure S1 (Supporting Information). The DSC based on R6 shows the $J_{\mathrm{sc}}$ of $12.65 \mathrm{~mA} \mathrm{~cm}{ }^{-2}$, the $V_{\mathrm{oc}}$ of $907 \mathrm{mV}$, the fill factor (FF) of 0.767 and the PCE of $8.8 \%$. In contrast, the DSC based on R7 exhibits a higher
$J_{\mathrm{sc}}$ of $13.91 \mathrm{~mA} \mathrm{~cm}^{-2}$ in good accordance with the integrated photocurrent density from IPCE, an enhanced $V_{\mathrm{oc}}$ of $980 \mathrm{mV}$, and an excellent FF of 0.785 , generating a PCE of $10.7 \%$. In Figure 2c, we investigated the relationship between $V_{o c}$ and different light intensities to calculate the value of ideality factor, yielding 1.79 and 1.55 for R6 and R7 devices, respectively. The smaller ideality factor of R7 based DSC reflects a depressed interfacial charger recombination, benefiting from the introduction of Hagfeldt donor in R7. To the best of our knowledge, R7 is the best performing blue sensitizer for copper-based DSCs. The statistics histogram of PCE of the R6 and R7 devices is presented in Figure 2d.

Table 1. Photovoltaic parameters of the best-performing devices under the simulated AM1.5C sunlight with varying light intensities.

\begin{tabular}{lcccccc}
\hline Dyes & $\begin{array}{c}\text { Sunlight } \\
{\left[\mathrm{mW} \mathrm{cm}^{-2}\right]}\end{array}$ & $\begin{array}{c}J_{S C}^{\text {IPCE }} \\
{\left[\mathrm{mA} \mathrm{cm}^{-2}\right]}\end{array}$ & $\begin{array}{c}\left.J_{\mathrm{sc}}^{\mathrm{b}}\right) \\
{\left[\mathrm{mA} \mathrm{cm}^{-2}\right]}\end{array}$ & $V_{\text {oc }}[\mathrm{mV}]$ & $\mathrm{FF}[\%]$ & PCE [\%] \\
\hline R6 & 100 & 12.30 & 12.65 & 907 & 76.7 & 8.8 \\
& 52.5 & & 6.62 & 881 & 75.5 & 8.4 \\
& 10.2 & & 1.20 & 803 & 65.8 & 6.2 \\
R7 & 100 & 13.75 & 13.91 & 980 & 78.5 & 10.7 \\
& 52.4 & & 7.30 & 955 & 80.3 & 10.7 \\
& 10.1 & & 1.35 & 889 & 79.7 & 9.5 \\
R7+Y123 & 100 & 15.84 & 16.15 & 1035 & 76.1 & 12.7 \\
& 50.5 & & 8.11 & 1003 & 80.1 & 12.9 \\
& 9.9 & & 1.56 & 940 & 77.7 & 11.5 \\
\hline
\end{tabular}

a) $J_{S C}^{I P C E}$ values were derived from IPCE spectra; b ${ }^{b} J_{s c}$ values were obtained from $J-V$ curves measured under standard AM1.5 G sunlight with varying light intensities. 

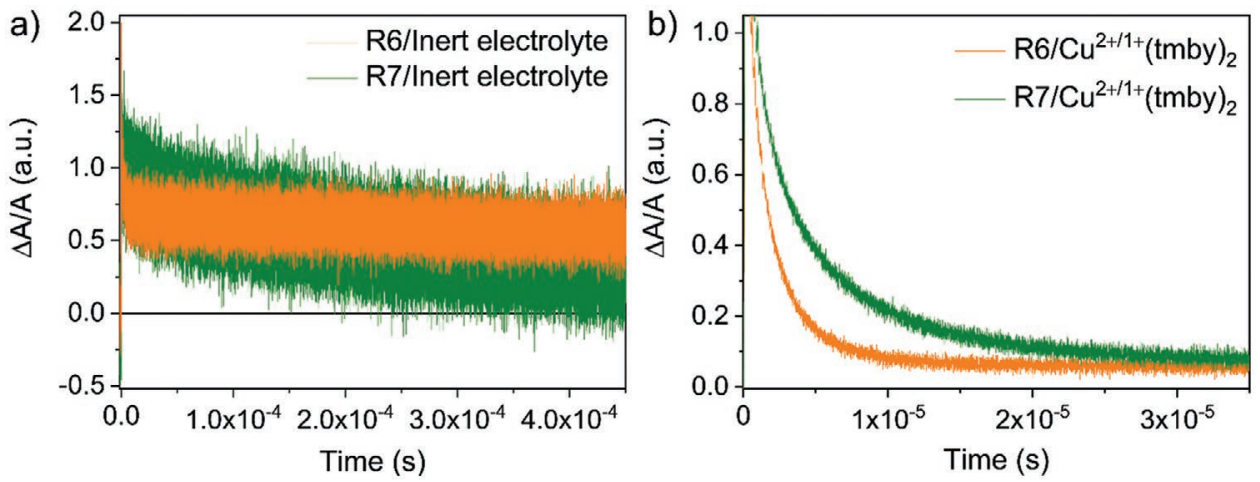

Figure 3. Transient absorption spectra for $\mathrm{R} 6$ and $\mathrm{R} 7$ sensitized $\mathrm{TiO}_{2}$ films a) with an inert electrolyte of $0.1 \mathrm{M}$ LiTFSI and $0.6 \mathrm{M} \mathrm{NMB}$ in acetonitrile, b) with $0.2 \mathrm{M}\left[\mathrm{Cu}^{+}(\mathrm{tmby})_{2}\right] \mathrm{TFSI}, 0.09 \mathrm{M}\left[\mathrm{Cu}^{2+}(\mathrm{tmby})_{2}\right](\mathrm{TFSI})_{2}, 0.1 \mathrm{M} \mathrm{LiTFSI}$ and $0.6 \mathrm{M} \mathrm{NMB}$ in acetonitrile. Pump wavelength, $650 \mathrm{~nm}$; probe wavelength, $900 \mathrm{~nm}$.

To investigate the cause of better performance of the R7 solar cell, TAS measurements were first performed to determine the effect of the bulkier donor moiety on the dye regeneration rate in copper-based electrolytes. The data was extracted and fitted with a multiexponential decay function (Figures S2 and S3, Supporting Information). For the dye-sensitized $\mathrm{TiO}_{2}$ films with an inert electrolyte composed of $0.1 \mathrm{M}$ LiTFSI and $0.6 \mathrm{M}$ 1-methylbenzimidazole (NMB) in acetonitrile, the decay signals (Figure 3a) are related to electron transfer from $\mathrm{TiO}_{2}$ to dye cation. The photogenerated electrons recombining with R7 cation have a recombination lifetime $\left(\tau_{\text {rec }}\right)$ of $175 \pm 3 \mu \mathrm{s}$, which is 13-fold slower than the ones with R6 cation being $13.4 \pm 0.6 \mu \mathrm{s}$. This result manifests the effects of molecular structure on the assembly of dye molecules on the surface of $\mathrm{TiO}_{2}$, which in turn affects the electrons in the $\mathrm{TiO}_{2}$ conduction band (CB) recombining with the dye cations. In the presence of $\left[\mathrm{Cu}(\mathrm{tmby})_{2}\right]^{2+/+}$ electrolyte, the accelerated decay signals (Figure $3 \mathrm{~b}$ ) imply the occurrence of hole injection from dye cation to copper(I) ions. Figure $3 \mathrm{~b}$ shows that the dye cations are regenerated fast. The regeneration lifetime $\left(\tau_{\text {reg }}\right)$ of the dye cations of $\mathrm{R} 7$ by the $\left[\mathrm{Cu}^{+}(\text {tmby })_{2}\right] \mathrm{TFSI}$ being $5.100 \pm 0.009 \mu \mathrm{s}$ is slightly slower than that of the R6 being $1.820 \pm 0.004 \mu \mathrm{s}$. The bulkier alkyl chains in the donor of R7 may have a steric hindrance of the dye regeneration process. Nevertheless, the regeneration efficiency $\left(\eta_{\text {reg }}\right)$ of R7 is calculated to be $97 \%$ according to Equation (1), which is higher than that of R6 being $88 \%$

$\eta_{\text {reg }}=\frac{\tau_{\text {rec }}-\tau_{\text {reg }}}{\tau_{\text {rec }}}$

The more efficient charge separation yield in the DSC with $\left[\mathrm{Cu}^{+}(\mathrm{tmby})_{2}\right]$ can account for a higher $J_{\text {sc }}$ of R7 than that of R6.

EIS experiments of devices under white light LED illumination with $100 \mathrm{~mW} \mathrm{~cm}{ }^{-2}$ were performed for an in-depth analysis of energetics and kinetic features of the electron transfer processes in the devices. The spectra were fitted to obtain the data by employing the ZView software, where the transmissionline model was employed. ${ }^{[38-40]}$ The results from the fittings are presented in Figure 4 The term $R_{\mathrm{CT}}$ refers to the recombination resistance of the $\mathrm{CB}$ electrons in the $\mathrm{TiO}_{2}$ with the $\mathrm{Cu}(\mathrm{II})$ in the electrolyte. The chemical capacitance, $C_{\mu}$, is in close relation to the available density of states (DOS) for the electrons in the semiconductor. The transport resistance, $R_{\text {trans }}$, is associated to the resistance opposed by the mesoporous $\mathrm{TiO}_{2}$ layer to electron transport through the film.

As shown in Figure 4a the $R_{\mathrm{CT}}$ is larger than $R_{\text {trans }}$, indicating that most of the photo-generated charges are collected instead of being lost by recombination. The $R_{\mathrm{CT}}$ of the DSC with R7 is higher than the counterpart with R6 under an applied voltage, denoting slower interfacial recombination. Additionally, the device with R6 presents higher transport resistance values than the one with R7. The plot for $C_{\mu}$ as a function of applied voltages in Figure 4a shows a slight difference for devices with R6 and R7. Figure 4b shows the voltage dependent DOS which is related to $C_{\mu}$, indicating the $\mathrm{CB}$ edge of $\mathrm{TiO}_{2}$ for $\mathrm{R} 7$ is slightly down-shifted compared to that for R6. As presented in Figure $4 \mathrm{c}$ at a certain DOS value, the electron recombination lifetime " $\tau_{\text {rec" }}$ " of EIS measurements for the device with R7 is significantly longer than that for the R6 based device. This result indicates that the Hagfeldt donor does play a significant role in decreasing electron recombination to the copper electrolyte, rendering a higher $V_{\mathrm{oc}}$. The transport time $\left(\tau_{\text {trans }}\right)$ of the device with R7 is shorter than that of R6 based counterpart at low DOS, which indicates a fast electron transport through the $\mathrm{TiO}_{2}$ layer to the external circuit under short-circuit conditions. The charge collection efficiency $\left(\eta_{\text {col }}\right)$ of R6 and R7 based DSCs is calculated according to Equation (2)

$\eta_{\mathrm{col}}=\frac{\tau_{\mathrm{rec}}}{\tau_{\text {trans }}+\tau_{\text {rec }}}$

As presented in Figure 4d the device with R7 has higher values of $\eta_{\text {col }}$ than the counterpart based on R6, which explains its larger $J_{\mathrm{sc}}$ and IPCE values.

To further improve the performance of DSCs, we chose the commonly used organic dye Y123 $3^{[37]}$ as a cosensitizer with the blue dye R7. As shown in Figure 5a, the cosensitized R7+Y123 based DSC exhibits outstanding photovoltaic parameters with the $J_{\mathrm{sc}}$ of $16.15 \mathrm{~mA} \mathrm{~cm}^{-2}$, the $V_{\text {oc }}$ of $1035 \mathrm{mV}$, and the $\mathrm{FF}$ of 0.76 , yielding an enhanced PCE of $12.7 \%$ under simulated standard AM 1.5G, $100 \mathrm{~mW} \mathrm{~cm}{ }^{-2}$. At a lower light irradiance of $50.5 \mathrm{~mW} \mathrm{~cm}{ }^{-2}$, the device efficiency reaches higher efficiency, up to $12.9 \%$, which can be attributed to the excellent FF (Table 1 and Figure S5, Supporting Information). The 

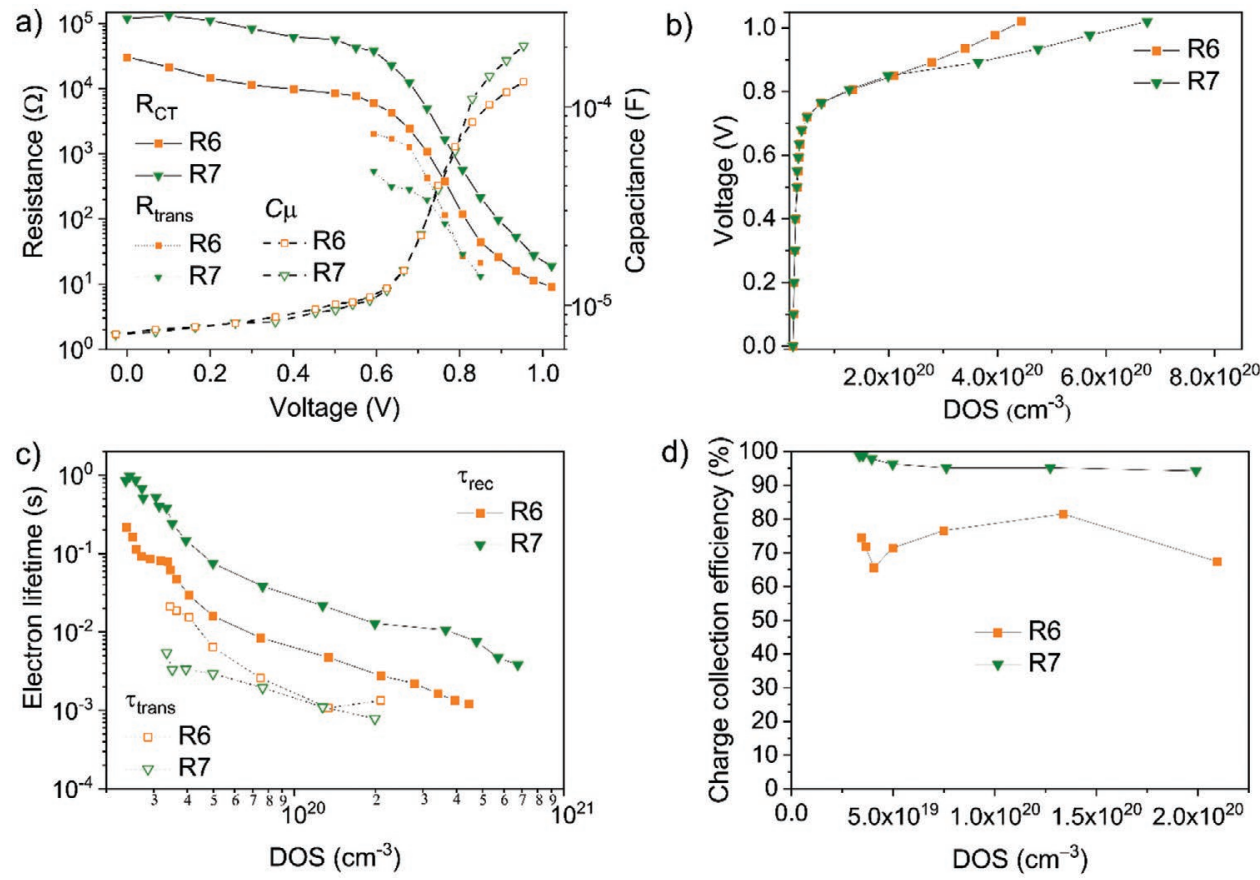

Figure 4. Electrochemical impedance spectroscopy (EIS) analysis. a) Continuous lines with solid markers describe the charge transfer resistance $\left(R_{\mathrm{CT}}\right)$ versus applied voltage. The dotted lines with solid markers present the transport resistance $\left(R_{\text {trans }}\right)$, and the dashed lines with open markers represent the chemical capacitance $\left(C_{\mu}\right)$. b) Voltage versus density of states (DOS). c) Electron lifetime as a function of DOS. d) Charge collection efficiency $\left(\eta_{\text {col }}\right)$ as a function of DOS
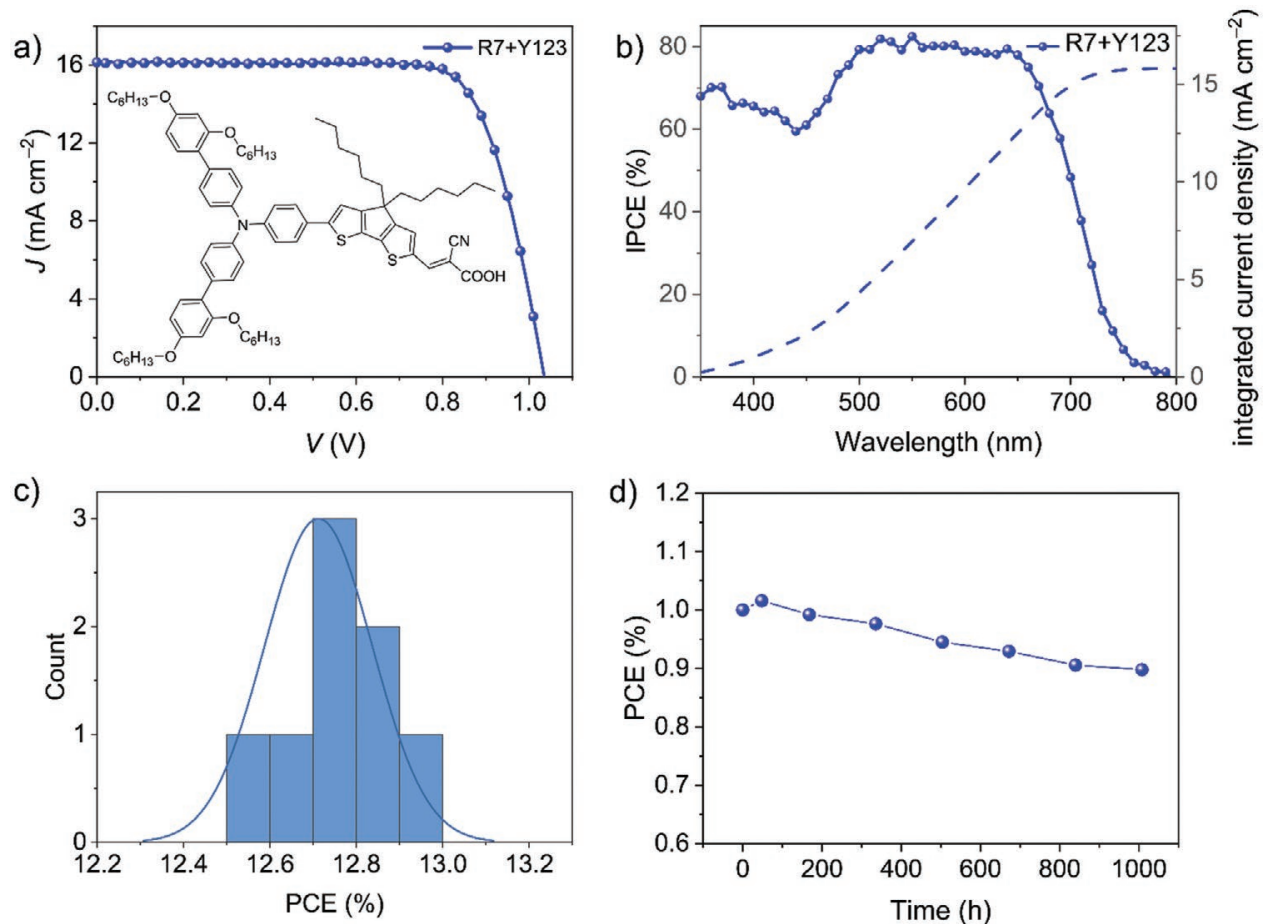

Figure 5. a) J-V curve of the DSC with the cosensitization of R7+Y123 under AM1.5 sunlight, $100 \mathrm{~mW} \mathrm{~cm}^{-2}$ condition. The inset shows the molecular structure of dye Y123. b) IPCE spectrum and integrated current density of the DSC with R7+Y123. c) Histogram of PCE of DSCs with R7+Y123 (eight samples). d) Evolution of normalized PCE of the DSCs with R7+Y123 measured under AM1.5 sunlight (100 mW cm $\mathrm{cm}^{-2}$ ) during the continuous light soaking at $45^{\circ} \mathrm{C}$ for $1000 \mathrm{~h}$. 
higher $J_{\mathrm{sc}}$ in cosensitized DSC compared to the R7 based one is manifested from the improved IPCE values. As shown in Figure $5 b$, the IPCE values of DSCs with $\mathrm{R} 7+\mathrm{Y} 123$ are remarkably enhanced within the measured wavelengths ranging from 400 to $600 \mathrm{~nm}$, with a peak value of $82 \%$. The scenario that cosensitization improves the $V_{\text {oc }}$ of DSCs has been presented in several reports. ${ }^{[26,29]}$ The PCE histogram of the R7+Y123 cell is presented in Figure 5c. The DSC based on sensitization of R7 and Y123 shows a remarkable stability, retaining $90 \%$ of its initial value after $1000 \mathrm{~h}$ of light soaking under 1 sun at $45{ }^{\circ} \mathrm{C}$ (Figure 5d). The detailed evolutions of photovoltaic parameters are presented in Figure S6 (Supporting Information).

\section{Conclusion}

To summarize, we judiciously designed and synthesized a new blue dye R7 featuring an auxiliary bulky Hagfeldt donor coupled with the strong electron releasing PAH core BPT2 and the famous acceptor EBTBA. This design successfully demonstrates the possibility to extend the spectral response of organic dyes with bulky donors for efficient copper electrolyte-based DSCs. The photovoltaic performance of R7-based DSCs with copperbased electrolytes largely outperforms the counterpart ones with R6 dye. DSC based on R7 has a higher $J_{\mathrm{sc}}$ and $V_{\mathrm{oc}}$ than the R6 based counterpart, mainly due to a decreased interfacial charge recombination, a more efficient charge separation yield, and a more efficient charge collection efficiency. The PCE of the blue dye R7 based DSC reaches 10.7\% under full sun light illumination condition. Furthermore, the co-sensitized system of $\mathrm{R} 7+\mathrm{Y} 123$ presented outstanding parameters of $J_{\mathrm{sc}}$ of $16.15 \mathrm{~mA} \mathrm{~cm}^{-2}, V_{\text {oc }}$ of $1035 \mathrm{mV}$, and FF of 0.76 , achieve a PCE of $12.7 \%$, while displaying a remarkable photostability. To the best of our knowledge, this is the highest value for copper-based DSCs using a blue photosensitizer. The result reveals that the Hagfeldt donor does play a significant role in DSCs with the copper complexes redox electrolyte. Our work provides guidance to future work on molecular design of other polycyclic aromatic hydrocarbonbased dyes with bulky donor and other electron-deficient segments for efficient and stable copper-electrolyte based DSCs.

\section{Experimental Section}

Materials: Acetonitrile (ABCR), tetrahydrofuran (THF) (ABCR), ethanol (EtOH) (Acros), 1-methylbenzimidazole (NMB) (TCl), and LiTFSI (TCI) were purchased from commercial companies and used as received. The powders of $\mathrm{Y} 123,\left[\mathrm{Cu}(\mathrm{I})(\mathrm{tmby})_{2}\right] \mathrm{TFSI}$, and $\left[\mathrm{Cu}(\mathrm{II})\right.$ (tmby) $\left.{ }_{2}\right]$ $(\mathrm{TFSI})_{2}$ were purchased from Dyenamo $\mathrm{AB}$ and used as received without further purification. R6 were synthesized according to the literatures. ${ }^{[7]}$ The synthetic routes to R7 are illustrated in Scheme S1 in the Supporting Information.

DSC Fabrication: The fabrications of the poly (3,4-ethylenedioxythiophene) counter-electrode and mesoporous $\mathrm{TiO}_{2}$ film

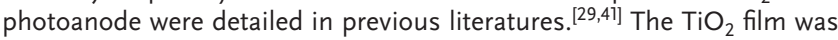
composed of $4.5 \mu \mathrm{m}$ thick colloidal $\mathrm{TiO}_{2}$ (Dyesol paste DSL 30 NRD-T) layer coupled with $4 \mu \mathrm{m}$ thick light-scattering $\mathrm{TiO}_{2}$ (Dyesol WER2-0) layer. The dye bath composition of single dye was $0.1 \times 10^{-3} \mathrm{M}$ R6 or R7 in THF/EtOH (1:4). The dye bath composition of the cosensitization system was $0.1 \times 10^{-3} \mathrm{M} \mathrm{R7}$ and $0.1 \times 10^{-3} \mathrm{M}$ Y123 in THF/EtOH (1:4). After immersion, all $\mathrm{TiO}_{2}$ films were rinsed in acetonitrile to remove any excess of dye. Solar cells were assembled according to the previous paper. ${ }^{[29]}$ The copper-based electrolyte consists of a solution of $0.2 \mathrm{M}$ $\left[\mathrm{Cu}(\mathrm{tmby})_{2}\right]$ (TFSI) and $0.09 \mathrm{M}\left[\mathrm{Cu}(\mathrm{tmby})_{2}\right](\mathrm{TFSI})_{2}$ complexes together with $0.1 \mathrm{M} \mathrm{LiTFSI}$ and $0.6 \mathrm{M} \mathrm{NMB}$ in acetonitrile. The inert electrolyte consists of $0.1 \mathrm{M} \mathrm{LiTFSI}$ and $0.6 \mathrm{M} \mathrm{NMB}$ in acetonitrile.

Electrochemical Measurements: Electrochemical experiments were carried out according to the previously reported method. ${ }^{[42]}$ The working electrode was mesoporous $\mathrm{TiO}_{2}(4 \mu \mathrm{m}$ thick film) deposited directly on FTO, i.e., without any underlayer.

Solar Cell Characterization: Measurements of current-voltage (I-V) characteristic curves, IPCE, and EIS were performed according to the method in our previous literature. ${ }^{[43]}$

Transient Absorption Spectroscopy: Nanosecond flash photolysis was used to monitor the dynamics. A frequency-tripled (355 nm) Q-switched Nd:YAG laser (continuum Surelite, $20 \mathrm{~Hz}$ repetition rate) was used to pump an optical parametric oscillator (GWU) allowing the excitation wavelength to be tuned. Both R6 and R7 samples were excited at $650 \mathrm{~nm}$. The samples were probed at $900 \mathrm{~nm}$ (Figure S4, Supporting Information) by a continuous Xenon arc lamp filtered by a monochromator with filters. The probe light was collected by a second monochromator and sent to a Silicon Amplified Photodetector (PDA 100A-EC, Thorlabs), enabling the photons to be converted into electrons. The induced transient voltage was recorded by a digital signal analyzer (DPO 7104C, Tektronix), and the data acquisition was averaged over 3000 shots to obtain a suitable signal-to-noise ratio.

\section{Supporting Information}

Supporting Information is available from the Wiley Online Library or from the author.

\section{Acknowledgements}

Y.R. and N.F.-D. contributed equally to this work. M.G. acknowledges the financial support from the European Union's Horizon 2020 Research and Innovation Program under grant Agreement No. 826013. P.W. acknowledges the financial support from National Natural Science Foundation of China (Nos. 51673165 and 91733302) and H. Glass. A.H. is grateful for the financial support of the Swiss National Science Foundation under contract SNSF 200020_185041. The authors thank Ladislav Kavan, from J. Heyrovsky Institute of Physical Chemistry, who helped them to test the cyclic voltammograms during his stay at EPFL.

\section{Conflict of Interest}

The authors declare no conflict of interest.

\section{Keywords}

blue dyes, chromophores, copper complexes, dye-sensitized solar cells

Received: June 5, 2020

Revised: July 31, 2020

Published online: September 13, 2020

[1] B. O'Reagan, M. Grätzel, Nature 1991, 353, 737.

[2] M. Zhang, J. Zhang, Y. Fan, L. Yang, Y. Wang, R. Li, P. Wang, Energy Environ. Sci. 2013, 6, 2939.

[3] K. Kakiage, Y. Aoyama, T. Yano, T. Otsuka, T. Kyomen, M. Unno, M. Hanaya, Chem. Commun. 2014, 50, 6379. 
[4] H. Nusbaumer, J. E. Moser, S. M. Zakeeruddin, M. K. Nazeeruddin, M. Grätzel, J. Phys. Chem. B 2001, 105, 10461.

[5] S. Hattori, Y. Wada, S. Yanagida, S. Fukuzumi, J. Am. Chem. Soc. 2005, 127, 9648.

[6] S. M. Feldt, E. A. Gibson, E. Gabrielsson, L. Sun, G. Boschloo, A. Hagfeldt, J. Am. Chem. Soc. 2010, 132, 16714.

[7] T. Daeneke, T.-H. Kwon, A. B. Holmes, N. W. Duffy, U. Bach, L. Spiccia, Nat. Chem. 2011, 3, 211.

[8] Y. Bai, Q. Yu, N. Cai, Y. Wang, M. Zhang, P. Wang, Chem. Commun. 2011, 47, 4376.

[9] A. Yella, H.-W. Lee, H. N. Tsao, C. Yi, A. K. Chandiran, M. K. Nazeeruddin, E. W.-G. Diau, C.-Y. Yeh, S. M. Zakeeruddin, M. Grätzel, Science 2011, 334, 629.

[10] Y. Saygili, M. Söderberg, N. Pellet, F. Giordano, Y. Cao, A. B. Muñoz-García, S. M. Zakeeruddin, N. Vlachopoulos, M. Pavone, G. Boschloo, L. Kavan, J. Moser, M. Grätzel, A. Hagfeldt, M. Freitag, J. Am. Chem. Soc. 2016, 138, 15087.

[11] A. Mishra, M. K. R. Fischer, P. Büuerle, Angew. Chem., Int. Ed. 2009, 48, 2474.

[12] Y. Wu, W. Zhu, Chem. Soc. Rev. 2013, 42, 2039.

[13] M. Liang, J. Chen, Chem. Soc. Rev. 2013, 42, 3453.

[14] S. Mathew, A. Yella, P. Gao, R. Humphry-Baker, B. F. E. Curchod, N. Ashari-Astani, I. Tavernelli, U. Rothlisberger, M. K. Nazeeruddin, M. Grätzel, Nat. Chem. 2014, 6, 242.

[15] Z. Yao, H. Wu, Y. Li, J. Wang, J. Zhang, M. Zhang, Y. Guo, P. Wang, Energy Environ. Sci. 2015, 8, 3192

[16] K. Kakiage, Y. Aoyama, T. Yano, K. Oya, J. I. Fujisawa, M. Hanaya, Chem. Commun. 2015, 51, 15894.

[17] Y. Ren, D. Sun, Y. Cao, H. N. Tsao, Y. Yuan, S. M. Zakeeruddin, P. Wang, M. Grätzel, J. Am. Chem. Soc. 2018, 140, 2405.

[18] Y. Kurumisawa, T. Higashino, S. Nimura, Y. Tsuji, H. liyama, H. Imahori, J. Am. Chem. Soc. 2019, 141, 9910.

[19] J. Ji, H. Zhou, Y. K. Eom, C. H. Kim, H. K. Kim, Adv. Energy Mater. 2020, 10, 2070070.

[20] K. Zeng, Y. Chen, W. H. Zhu, H. Tian, Y. Xie, J. Am. Chem. Soc. 2020, 142, 5154.

[21] M. A. Green, E. D. Dunlop, J. Hohl-Ebinger, M. Yoshita, N. Kopidakis, A. W. Y. Ho-Baillie, Prog. Photovoltaics Res. Appl. 2020, $28,3$.

[22] A. Fakharuddin, R. Jose, T. M. Brown, F. Fabregat-Santiago, J. Bisquert, Energy Environ. Sci. 2014, 7, 3952.

[23] P. Wang, L. Yang, H. Wu, Y. Cao, J. Zhang, N. Xu, S. Chen, J. D. Decoppet, S. M. Zakeeruddin, M. Grätzel, Joule 2018, 2, 2145.

[24] M. Freitag, Q. Daniel, M. Pazoki, K. Sveinbjörnsson, J. Zhang, L. Sun, A. Hagfeldt, G. Boschloo, Energy Environ. Sci. 2015, 8, 2634.
[25] Y. Cao, Y. Saygili, A. Ummadisingu, J. Teuscher, J. Luo, N. Pellet, F. Giordano, S. M. Zakeeruddin, J. E. Moser, M. Freitag, A. Hagfeldt, M. Grätzel, Nat. Commun. 2017, 8, 15390.

[26] M. Freitag, J. Teuscher, Y. Saygili, X. Zhang, F. Giordano, P. Liska, J. Hua, S. M. Zakeeruddin, J. Moser, M. Grätzel, A. Hagfeldt, Nat. Photonics 2017, 11, 372.

[27] W. Zhang, Y. Wu, H. W. Bahng, Y. Cao, C. Yi, Y. Saygili, J. Luo, Y. Liu, L. Kavan, J. Moser, A. Hagfeldt, H. Tian, S. M. Zakeeruddin, W. Zhu, M. Grätzel, Energy Environ. Sci. 2018, 11, 1779.

[28] Y. Liu, Y. Cao, W. Zhang, M. Stojanovic, M. I. Dar, P. Péchy, Y. Saygili, A. Hagfeldt, S. M. Zakeeruddin, M. Grätzel, Angew. Chem., Int. Ed. 2018, 57, 14125 .

[29] Y. Cao, Y. Liu, S. M. Zakeeruddin, A. Hagfeldt, M. Grätzel, Joule 2018, 2, 1 .

[30] H. Jiang, Y. Ren, W. Zhang, Y. Wu, E. C. Socie, B. I. Carlsen, J.-E. Moser, H. Tian, S. M. Zakeeruddin, W.-H. Zhu, M. Grätzel, Angew. Chem., Int. Ed. 2020, 59, 9324.

[31] H. Michaels, M. Rinderle, R. Freitag, I. Benesperi, T. Edvinsson, R. Socher, A. Gagliardi, M. Freitag, Chem. Sci. 2020, 11, 2895.

[32] K. Kannankutty, C.-C. Chen, V. S. Nguyen, Y.-C. Lin, H.-H. Chou, C.-Y. Yeh, T.-C. Wei, ACS Appl. Mater. Interfaces 2020, 12, 5812.

[33] Y. Saygili, M. Stojanovic, H.-S. Kim, J. Teuscher, R. Scopelliti, M. Freitag, S. M. Zakeeruddin, J.-E. Moser, M. Grätzel, A. Hagfeldt, J. Phys. Chem. C 2020, 124, 7071.

[34] B. C. O'Regan, J. R. Durrant, Acc. Chem. Res. 2009, 42, 1799.

[35] T. Stergiopoulos, P. Falaras, Adv. Energy Mater. 2012, 2, 616.

[36] M. J. Griffith, K. Sunahara, P. Wagner, K. Wagner, G. G. Wallace, D. L. Officer, A. Furube, R. Katoh, S. Mori, A. J. Mozer, Chem. Commun. 2012, 48, 4145.

[37] H. N. Tsao, C. Yi, T. Moehl, J. H. Yum, S. M. Zakeeruddin, M. K. Nazeeruddin, M. Grätzel, ChemSusChem 2011, 4, 591

[38] F. Fabregat-Santiago, J. Bisquert, G. Garcia-Belmonte, G. Boschloo, A. Hagfeldt, Sol. Energy Mater. Sol. Cells 2005, 87, 117.

[39] T. Marinado, K. Nonomura, J. Nissfolk, M. K. Karlsson, D. P. Hagberg, L. Sun, S. Mori, A. Hagfeldt, Langmuir 2010, 26, 2592.

[40] F. Fabregat-Santiago, G. Garcia-Belmonte, I. Mora-Seró, J. Bisquert, Phys. Chem. Chem. Phys. 2011, 13, 9083.

[41] H. Ellis, N. Vlachopoulos, L. Häggman, C. Perruchot, M. Jouini, G. Boschloo, A. Hagfeldt, Electrochim. Acta 2013, 107, 45.

[42] L. Kavan, Z. V. Zivcova, M. Zlamalova, S. M. Zakeeruddin, M. Grätzel, J. Phys. Chem. C 2020, 124, 6512.

[43] N. Flores-Díaz, H.-W. Bahng, N. Vlachopoulos, J.-E. Moser, S. M. Zakeeruddin, M. Grätzel, A. Hagfeldt, J. Mater. Chem. A 2019, 7, 10998. 